BONPLANDIA 20(2): 419-426. 2011

ISSN: 0524-0476

\title{
SEMBRAR, PLANTAR, CULTIVAR, DOMESTICAR
}

\author{
ANTONIO KRAPOVICKAS ${ }^{1}$
}

\author{
"Je sème a tout vent" \\ Pequeño Larousse Ilustrado
}

Cuando se trata de desentrañar los comienzos de la domesticación y los orígenes de la agricultura es conveniente aclarar conceptos, algunos de los cuales son muy usados en el leguaje común, pero no siempre en forma acertada.

El Arcaico Inferior (4000 a $2500 \mathrm{aC}$ ) es una etapa que se caracteriza por un modo de producción predominantemente recolector con ensayos avanzados en la domesticación de algunas plantas (Lumbreras, 1967: 264). Pero esta domesticación tiene que estar asociada con el comienzo del cultivo, sin el cual es inconcebible el proceso que requiere una buena dosis de selección. Es el caso de sembrar y plantar, que muchas veces se usan indistintamente.

Sembrar deriva del latín seminare, "arrojar y esparcir las semillas en la tierra preparada para este fin" (R.A.) y sus derivados, sembradío, sembrado, sembrador, sembradora, siembra (to seed, to sow).

Plantar deriva del latín plantare "meter en tierra una planta o un vástago, esqueje, etc., para que arraigue" (R.A.) y sus derivados plantío, plantación, plantador (to plant).

Una excepción la constituye el uso de la expresión "papa semilla", "tubérculo semilla" o "semilla de papa" aplicado al tubérculo o parte de éste utilizado para la multiplicación. De acuerdo al tamaño o calibre del tubérculo, se distinguen varios tipos: "Cohillo", "Semillita". Semilla", "Semillón" y "Consumo" (Anónimo, 1979). Sin embargo la máquina utilizada se llama "plantadora de papa" (Burba, 1985).

Según la Ley de Semillas y Creaciones
Fitogenéticas n 20247/73 "se entiende por semilla o simiente, todo órgano vegetal, tanto semilla en sentido botánico estricto como también frutos, bulbos, tubérculos, yemas, estacas, flores cortadas y cualquier otra estructura, incluyendo plantas de vivero, que sean destinadas o utilizadas para siembra, plantación o propagación". Usa el término en sentido muy amplio, pero discrimina siembra de plantación.

Cultivos de plantación: azucar, café, cacao, goma, té, banana, sisal, cáñamo, henequén, algodón. Estos recuerdan la época en que esos productos provenían en su mayor parte de "plantaciones" de ultramar. La palabra plantación comenzó a significar cultivo de cosechas para exportar (Graves, 1960), y asociadas a industrias. Salvo el algodón, son todos cultivos perennes y en gran medida de multiplicación vegetativa.

Hay diferencias entre sembrar y plantar que encaminan el proceso de domesticación por dos vías evolutivas diferentes. En general las semillas provienen del proceso de fecundación sexual, excepto las semillas apomícticas. La fecundación sexual involucra la recombinación genética que asegura un alto grado de variabilidad. En las poblaciones no hay dos individuos idénticos.

En cambio con la multiplicación vegetativa se reproducen individuos idénticos o clones. La variabilidad de las poblaciones resultantes es nula o muy reducida. Este método de multiplicación permite solamente seleccionar mutaciones y elimina la recombinación de carácteres. Posibilita la perpetuidad de híbridos, individuos estériles como triploides,

\footnotetext{
${ }^{1}$ Instituto de Botánica del Nordeste, Casilla de Correo 209, 3400 Corrientes, Argentina.
} 
pentaploides y otros. En algunos casos como el del ananá y el banano, la especie cultivada solamente se multiplica vegetativamente y perdió totalmente la capacidad de producir variabilidad por recombinación. En el lenguaje corriente esta diferencia ha sido captada. Decimos "sembrar ideas" y no "plantarlas". La diferencia es clara, sembrar está asociado con fecundidad y con la posibilidad de mayor multiplicación y amplia dispersión. También hay diferencias sociales. El sembrador parece ser un hombre más libre que el plantador.

Cultivar se refiere al cuidado que el hombre da a las plantas para criarlas. Incluye labranza (tillage), siembra (seeding), desyerbe (weeding), control de pestes (pest control), cosecha (harvesting), etc. (Harlan, 1981).

Es frecuente encontrar en la literatura la presunción de que las plantas domesticadas deben sus caracteres a la acción continuada del cultivo. El cultivo basa su efecto en una condición de la especie que es la plasticidad; esta condición, mucho más amplia en los vegetales que en los animales, permite que ciertas especies puedan desarrollarse en condiciones muy diversas. Según la tierra, los nutrientes y la humedad disponibles, la misma especie puede llegar a completar su desarrollo en forma muy precaria o adquirir un tamaño exuberante. Pero esta variabilidad generalmente no es hereditaria (Parodi, 1938: 16).

Cultivo, es la especie cultivada, equivale al inglés "crop" o al francés "culture" (León, 1987). El término en su sentido amplio abarca todas las cosechas sin tener en cuenta su estado de domesticación.

Domesticación, deriva del latín "domus", casa. La domesticación se refiere a los cambios genéticos producidos en plantas bajo cultivo. Es un proceso evolutivo que tiene lugar gradualmente en el tiempo y hay toda clase de grados y estadios de condiciones intermedias. La planta silvestre es parte natural de la flora nativa y puede sobrevivir sin ninguna clase de actividad humana. En el otro extremo una planta totalmente domesticada depende para su supervivencia del cuidado e intervención humana.

Cultígeno es la planta cultivada cuya conexión con sus antecesores silvestres se han perdido y que en la mayoría de los casos dependen del cuidado del hombre para su supervivencia. En numerosos casos han perdido la capacidad de producir semillas o son incapaces de mantenerse por sí mismos (Sauer, 1950: 489).

Malezas (weed) son organismos que prosperan en habitats modificados por el hombre y que pueden llegar a ser indeseables. Junto con el cultivo forman parte de un agroecosistema constituido por un ensamble de cultivos, ganado, pestes, plagas, alambrados, máquinas e instalaciones varias (Soriano y Aguiar, 1997). La relación de los cultivos con las malezas es muy compleja. Hay cultivos que derivaron de malezas y también hay malezas que derivaron de cultivos.

Cuandocomenzó el cultivo es casi imposible determinarlo. Muchos pueblos considerados no agricultores han practicado algún cultivo. Los indios "pies negros", al igual que otras tribus de las Praderas de América del Norte, dependían para su alimentación de la caza y de la recolección, no obstante cultivaban tabaco. Se labraba una parcela cerca del campamento de invierno y a comienzos de la primavera eran sembradas las semillas del tabaco; esta tarea era realizada de modo ceremonial por hombres. La cosecha era recogida cuando el grupo regresaba en otoño a sus cuarteles de invierno (Forde, 1966: 81).

Hasta nuestros días se practica alguna forma de recolección y caza. Podemos mencionar la recolección de hongos y frutas silvestres y la cacería que no ha perdido adeptos.

De acuerdo a la ley de Hardy-Weinberg las frecuencias relativas de los diversos alelos de un gen existentes en una población mendeliana tienden a permanecer constantes indefinidamente. Sin embargo hay fuerzas que perturban el equilibio génico y modifican las frecuencias génicas de las poblaciones. Estas fuerzas que pueden explicar los cambios evolutivos son: mutación, recombinación génica, selección, deriva genética al azar en poblaciones pequeñas, aislamiento reproductivo y migración diferencial y tienen lugar en los procesos de domesticación.

El principio de la selección natural ha sido señalado por primera vez en 1813 y 1818 por W.C. Wells, como lo consigna Darwin en la 
Noticia Histórica de su obra El origen de las especies, pero es Darwin el que demuestra el efecto de la selección natural en el origen de las especies. El cultivo seguido de la selección ejercida por el hombre primitivo ha producido la domesticación de las plantas cultivadas.

Las presiones de selección que actúan durante el cultivo son de varias clases. Por un lado la selección de los mejores productos alimenticios y por otro las labores de siembra y de recolección que tienden a uniformar la germinación y la adaptación a la cosecha a favor de frutos no caedizos como raquis tenaz en los cereales o clavo no quebradizo en el maní.

Los comienzos del cultivo y del proceso de domesticación son muy remotos y no quedan restos arqueológicos que los documenten. Solamente disponemos de información biológica referente al parentesco de los actuales animales y plantas domésticas.

No es difícil imaginar a los recolectores primitivos, con su conocimiento profundo de la naturaleza, observar repetidamente después de una lluvia o de una quemazón germinar las semillas de las plantas que busca y utiliza. Después de remover el suelo en busca de raíces o tubérculos, se produce cortes y heridas en las partes subterráneas de las plantas, provocando la multiplicación vegetativa y proliferación de nuevos individuos.

El período de iniciación del cultivo se denomina indistintamente hortícola, cultivo incipiente o experimental, agricultura incipiente, protoagricultura o preagricultura. Comienza asociado con la recolección y la caza y se lo diferencia de la agricultura.

El período de agricultura incipiente es una etapa cultural donde comienzan a llegar las plantas cultivadas, pero donde el nivel de la cultura general es aún muy bajo ya que carece de alfarería, metales y textiles elaborados. Las culturas conocidas de nuestro país aparecen plenamente formadas con ganadería, alfarería y plantas cultivadas (González y Pérez, 1972: 38).

"Entre los peruanismos que vengo estudiando, hay algo muy significativo: se trata de las palabras gormay y huarmay, vocablos que aluden, como sinónimo, a una práctica actualmente en uso en el Departamento de
Huánuco y que consiste en seleccionar los mejores frutos de las cosechas y las mejores comidas para ser guardadas y consumidas con posterioridad (Javier Pulgar Vidal, inédito, 1980, tomado de Bonavia, 1982: 254).

La primera evidencia tangible del cultivo de plantas domesticadas marca el principio de la época de la agricultura incipiente (Towle, 1961: 138).

Armillas (1956) agrupa a las diversas culturas indígenas en tres épocas y utiliza para establecer esta división la aparición de la agricultura y su desarrollo. Fija así tres etapas: 1) la preagrícola, de pueblos recolectores, cazadores y pescadores, desde la llegada del primer habitante (unos 25.000 años a.C.) hasta 3.000 a.C.; 2) la protoagrícola, desde 3.000 hasta 500 a.C, con pueblos de cultivadores de aldea y en la que se produjo la expansión del cultivo desde sus centros de origen, y 3) desde la aparición de las civilizaciones en Mesoamérica y el área andina de Sudamérica, en 500 a.C., hasta 1.500 d.C. Esta última época marca la transición de las culturas agrícolas con una organización tribal de aldea a una más compleja de tipo estatal.

Agricultura (del latín ager, agri, campo y cultura, cultivo). Labranza o cultivo de la tierra. Arte de cultivar la tierra (R.A.). Entre las primeras plantas cultivadas figura la Lagenaria siceraria, de origen africano y encontrada en niveles más antiguos tanto en Tamaulipas (México) como en Ayacucho (Perú) (Richardson, 1972).

La capacidad de expansión de la especie humana se manifiesta por ser la única especie que se ha extendido en toda la superficie de la Tierra y ocupado cuanto nicho o refugio encontró a su paso en busca de protección. El aislamiento se manifiesta en la multiplicidad de lenguas y dialectos indoamericanos, unos 2.000 según Castellvi y Espinosa (1958). Esta falta de comunicación se combinó con una capacidad de migración y comunicación notable. No hay otra explicación para la difusión del cultivo del maíz, que en el momento de la conquista se extendió desde Canadá hasta el centro de Chile y Argentina $\left(35^{\circ}\right.$ lat. S) y cuyo origen está establecido en el centro de México. Lo mismo sucedió con el maní, de origen indudable en en el 
sur de Bolivia y que se extendiera su cultivo desde Córdoba en Argentina hasta Tehuacán (México) e Isla Española, en el Caribe

Los movimientos de las bandas primitivas seguían caminos más o menos definidos, dentro de su propio territorio. Tenemos la trashumancia practicada unicamente por los pueblos pastores que en América estaría limitada a los pueblos andinos que domesticaron la llama y la alpaca, en la Puna con lluvias solamente en el verano. En las punas, jalcas y cordilleras de las Andes Centrales de Perú, húmedas todo el año, la trashumancia ha sido puesta en duda por Cardich (1976). Otro movimiento que podemos denominar itinerante, era practicado por casi todas las bandas recolectoras y cazadoras, que seguían un circuito más o menos constante en busca de recursos alimenticios, como los Paipai y sus vecino de Baja California (Hicks, 1965). Muchas veces asociaban sus recorridos con cultivos en muy pequeña escala, como los Pies Negros, con el tabaco (Forde, 1966: 81) o como los Kaigangues de Misiones, con cultivos reducidos de maíz y zapallo (Ambrosetti, 1895: 307)

La trashumancia (transhumance en francés [Leroi-Gourham, 1988] y en inglés [Winick, 1961]) tiene diversas acepciones. La original y más generalizada se refiere a los movimientos estacionales de los animales domésticos desde una zona a otra en la que prevalecen condiciones climáticas diferentes (Winick, 1969; Echeverría, 1981; Alcina Franch, 1998). Es un término usado en España, en donde hasta hace poco tiempo estaba excepcionalmente bien desarrollada (Forde, 1966: 419). Se practica en regiones montañosas como los Pirineos o los Alpes (Stephens, 1998: 256)

Otra interpretación que se está generalizando en nuestros países americanos, es la de aplicar el término trashumncia a todo movimiento de poblaciones humanas ya sean ganaderas o nó. Fué aplicado por Lynch (1971 y 1975) a la migración estacional, cuando se reunían las condiciones requeridas: estaciones alternantes y gran variedad de nichos ecológicos desde el mar hasta los nevados, en el Callejón de Huaylas, en Perú.

Creo conveniente mantener el significado original de trashumancia, referido al movimiento estacional del ganado, porque es posible que se relacione con el proceso de domesticación animal. Para los movimientos de las bandas de cazadores recolectores prefiero utilizar la palabra itinerante, pués estos pobladores primitivos en general recorrían un camino o itinerario perfectamente establecido dentro de su territorio, de acuerdo a la disponibilidad de caza o pesca y de la madurez de los productos vegetales.

Además del famoso camino del Inca, en las llanuras existía el camino, que unía a los guaraníes de la costa atlántica con los de tierra adentro,hasta el río Paraguay, denominado peabirú, tenía un ancho de ocho palmos y lo cubría gramilla muy menuda (Cardozo, 1989: 39; Prous, 1992: 374).

La base del mejoramiento fitotécnico consiste por un lado obtener uniformidad de los cultivares por consanguinidad o endogamia: líneas puras o consanguíneas. Por otro lado provoca variabilidad por medio de cruzamientos para seleccionar nuevas combinaciones génicas. Es una combinación de endogamia y exogamia

Exogamia y endogamia son términos creados por McLennan en 1865 en su obra Primitive Marriage para la obligación de contraer matrimonio fuera del grupo y la obligación de contraerlo dentro de una determinada agrupación de personas, respectivamente. Estos términos fueron adaptados por la moderna genética y equivalen a "outbreeding" e "inbreeding".

La variabilidad que presentan los cultígenos solo es comparable con la de la especie humana y no se encuentra en ninguna otra especie silvestre en la naturaleza. Como los cultígenos dependen exclusivamente de la actividad humana para sobrevivir, acompañan al hombre en todos sus movimientos y constituyen un caso de coevolución muy complejo. En la naturaleza hay muchos ejemplos de coevolución, entre los cuales los de simbiosis son los más extremos. Durante el proceso de domesticación se establece una relación hombre-animal o planta doméstica similar al de la simbiosis, en la que las dos partes tienen beneficios y no pueden existir sin depender una de la otra (Higgs \& Jarman, 19). La diferencia entre la naturaleza, en que la 
simbiosis se establece generalmente entre dos especies o simbiontes, y la especie humana es capaz de convivir en estrecha relación simbiótica con muchas especies al mismo tiempo.

Los movimientos de las comunidades humanas primitivas provocan los efectos de la endogamia, cuando hay aislamiento y posibilitan la exogamia con sus movimientos migratorios o itinerantes, tanto en la comunidad humana como en las poblaciones de plantas cultivadas que llevan consigo.

Con el inicio del cultivo el hombre comenzó a crear nuevos ambientes o agroecosistemas, en los cuales, tanto las plantas cultivadas como sus acompañantes, malezas y parásitos, viven en condiciones muy parecidas en cualquier parte de la superficie terrestre, con gran independencia de los ecosistemas naturales.

En los lugares donde los cultígenos viven en contacto con sus parientes silvestres se mantiene cierto flujo de genes por introgresión. En estos microgenocentros en el sentido de Zhukovsky (1970).

Al localizar los centros de variación de las plantas cultivadas se establecen también las cunas de las grandes civilizaciones (Vavilov, 1951: 120). Encuentra Vavilov que los centros de variación se hallan en zonas montañosas, donde el relieve provee más ambientes heterogéneos que en el llano. El contacto entre comunidades agrícolas aisladas entre sí por accidentes geográficos es menos frecuente que en la llanura. Áreas montañosas con sus semiaisladas comunidades agrícolas con cultivos en manchas por un lado y con gran amplitud de climas y suelos por otro lado se adecúan al modelo de Sewal Wright para una rápida evolución (Zohary, 1970). Con la migración se alejan los cultígenos de sus parientes silvestres y se acentúan las diferencias al cesar el flujo de genes entre ellos.

El origen de la cocina debe ser muy antiguo. Entre los mitos sobre el origen del fuego (Frazer, 1942) buena parte de ellos mencionan que debían comer cruda su comida y que con el fuego pudieron cocer, tostar o asar sus alimentos, tanto de origen vegetal como animal. Otra prueba es la gran antigüedad de los molinos de mano o morteros para moler granos. La técnica de la molinería de los granos duros se cree hoy que presenta una antigüedad cercana a los 40.000 años en África austral (Carter, 1978; López Girón, 1993).

La relación de la cocina con el proceso de domesticación se manifiesta en el hecho de que la gran mayoría de los cultígenos que constituyen la base de la agricultura, se consumen unicamente cocidos o asados, salvo frutas y muchas hortalizas.

Gastronomía o arte culinario. El control del fuego permitió que el ser humano. además de lograr un más amplio dominio de su entorno, realizara por vez primera una sistemática transformación de sus alimentos. que antes ingería crudos. El fuego facilitó la digestilibidad de los mismos e hizo posible que se diversificara su preparación, con lo que se abrió un nuevo mundo para la humanidad.

Casi todos los cultígenos ya estaban presentes unos 2.500 años A.C.

Conviene diferenciar la domesticación de la agricultura (Zohary, 1992; Hather 1996; Krapovickas, 1996, 1997) como dos procesos íntimamente ligados entre sí pero con diferente desarrollo. La domesticación es un proceso principalmente biológico, por el cual se obtienen plantas y animales diferentes, tanto cualitativamente como por sus rendimientos, de sus parientes silvestres. En cambio la agricultura como conjunto de técnicas para aumentar y asegurar la producción, es un proceso principalmente cultural.

En el yacimiento de Tell Abu Hureyra, en el norte de Siria, en el límite del valle del Eufrates, excavado por Andrew Moore a principios de los años 70 (Renfrew \& Bahn, 1993: 266), se obtuvo una imagen expresiva de una economía de subsistencia. Fue ocupado en el Epipaleolítico (10000 a 9000 AC) y de nuevo en el Neolítico (después del 7500 $\mathrm{AC}$ ). En el período más antiguo, el $90 \%$ de la dieta vegetal se basaba en 160 especies. En el Neolítico, sólo 8-9 especies cultivadas (cereales: 5 especies, legumbres: 3-4 especies) suministraban un porcentaje similar de la dieta. Estos cuadros nos muestran que una vez adoptados los nuevos cultígenos, éstos desplazan a las especies silvestres de la dieta terminando un período de búsqueda, 
utilización y experimentación de recursos naturales. Si el proceso de domesticación fue realizado en el mismo lugar tendríamos una medida del tiempo que demandó dicha domesticación: no más de 1500 a 2000 años.

$7000 \mathrm{AC}$ en la actual Turquía, la primitiva aldea agrícola de Çatal Hüyük ya está organizada en tribu con construcciones aglomeradas (Renfrew \& Bahn, 1993: 164).

En América se generalizó la siembra de tres cultígenos, muchas veces asociados, maíz, poroto y zapallo. En la mitología de los iroqueses, de la región de los Grandes Lagos y del río San Lorenzo, las Tres Hermanas, el Espíritu del Maíz, el Espíritu de los Porotos y el Espíritu de los Zapallos, que se suponía tenían la forma de hermosas mujeres, encariñadas entre sí y que gozaban de vivir juntas. Esta última idea está ilustrada por la natural adaptación de las plantas mismas de crecer juntas en el mismo terreno (Morgan, 1851: 161).

En la costa santefecina del río Paraná, según los primeros cronistas, se practicaba una agricultura basada en el maíz, porotos y zapallos, asociada con aldeas permanentes.

En la quebrada de Yariguarenda, a pocos $\mathrm{kms}$ al norte de Tartagal (Salta), área de influencia chiriguano-chané, he visto un cultivo asociado de maíz con poroto, trepando por la caña, y Cucurbita, entre las líneas, realizado por un criollo. Lo interesante en esta asociación es que donde la Cucurbita cubría el suelo no había malezas y el poroto tenía un sostén para trepar.

Las etapas del proceso de domesticación serían:

Multiplicación inducida por el hombre (sembrar o plantar), de origen y fecha incierta, pero que se articula con la "caza y recolección".

El cultivo, por pequeño que sea, contribuye a reducir los desplazamientos en búqueda de alimentos.

Comienzo de creación de un nuevo ambiente, un agroecosistema, en el conviven el hombre, las plantas y animales útiles, sus parásitos, plagas y malezas. Cambiando las condiciones del suelo, es posible extender los cultivos a nuevos ambientes gracias a la capacidad diseminadora del hombre

Domesticación. El cultivo tiene que estar acompañado de selección. Los primeros pasos habrían sido realizados por bandas de cazadores-recolectores, en lugares donde crecían naturalmente las especies progenitoras, que se multiplicarían sin mucho cuidado, al voleo o utilizando el palo recolector.

Agricultura incipiente, marcada por el hallazgo de los primeros restos arqueológicos de cultígenos. Etapa (Orquera, 1974: 187). Se incorporan nuevas herramientas como la azada o la pala que permiten ampliar el área de cultivo, ya sea por movimiento de tierra o el inicio de sistemas de riego.

Agricultura de susbsistencia.

Agroalfarero, Etapa (Orquera: 1870)

Agricultura de aldea, cierto grado de sedentarismo basado en el cultivo de maíz, porotos y zapallos.

Agricultura con incremento de cultivos

Agricultura.

Con la creación del nuevo agroecosistma, el hombre, por medio del cultivo, comienza a independizarse del ambiente, posibilitando la extensión de sus cultivos a nuevas áreas, ampliando sustancialmente sus posiblidades de subsistencia. Especialmente con la incorporación de nuevos utensillos (pala, azada) y nuevas técnicas (riego, desagüe, montículos) el hombre primitivo pudo ocupar nuevas áreas, desarrollando una agricultura que posibilitó el desarrollo de comunidades sedentarias.

\section{Bibliografía}

ALCINAFRANCH, J. 1998. Diccionario de Arqueología. Alianza Editorial, Madrid.

AMBROSETTI, J. B. 1895. Los indios Kaingangues de San Pedro (Misiones). Revista del Jardín Zoológico, Buenos Aires 2(10): 305-387.

ANÓNIMO. 1979. Como el productor puede mejorar su propia semilla de papa. Boletín Técnico 38. Estación Experimental Remehue, Osorno, Chile.

ARMILLAS, P. 1956. Cronología y periodificación de la 
historia de la América Precolombina. En Cuadernos de Historia Mundial, 3(2): 463-503. Neuchâtel.

BURBA, J.L., H.M. FONTÁN \& M.I. BUTELER, 1985. Fichas Técnicas de Maquinaria de uso Hortícola. Santa Fé, Argentina.

CARDICH,A. 1976. Vegetales y recolecta en Lauricocha: Algunas inferencias sobre asentamientos y subsistencia preagrícolas en los Andes Centrales. Relaciones. Soc. Argent. Antropología 10: 27-41.

CARDOZO, E. 1989. Paraguay de la conquista. El Lector, Asunción.

CARTER, G.F. 1978. The American Paleolitic. En Early man in America, from a Circum-Pacific Perspective, ed. A.L. Bryan. Occasional Papers No 1 of the Department of Anthropology, University of Alberta, Canadá.

CASTELLVI, M. \& L. ESPINOSA PÉREZ. 1958. Propedeutica etnioglotologica y diccionario clasificador de las lenguas indoamericanas. Madrid.

ECHEVERRÍA, A.J. 1981. Glosario Arqueológico. Instituto Otavaleño de Antropología, Ecuador.

FLANNERY, K. V. 1975. La evolución cultural de las civilizaciones. Editoral Anagrama, Barcelona. Edición original: The cultural evolution of civilizations, Annual Review of Ecology and Systematics, 1972.

FORDE, C.D. 1966. Habitat, Economía y Sociedad. Oikos-tau, Barcelona.

FRAZER, G.J. 1942. Mitos sobre el origen del fuego en América. Emecé Editores, Buenos Aires.

GREAVES, I.C. 1960. Las plantaciones en la economía mundial. en Sistemas de plantaciones en el nuevo mundo. Unión Panamericana. Washington.

HATHER, J.G. 1996. The origins of tropical vegeculture: Zingiberaceae, Araceae and Dioscoreaceae in Southeast Asia. En The origins and spread of agriculture and pastoralism in Eurasia, ed. D.R. Harris: 538-550.

HERNÁNDEZ BERMEJO, J.E \& J. LEÓN (ed.). 1992. Cultivos marginados. Otra perspectiva de 1492. Colección FAO, Producción Vegetal 26: 163-177. Roma.

HICKS, F. 1965. La etnobotánica y el estudio de la Ecología Cultural. Suplemento Antropológico, Revista Ateneo Paraguayo 1(1): 15-25.

HIGGS, E.S. \& M.R. JARMAN. 1969, The Origins of Agriculture: a Reconsideration. Antiquity 43: 3141.

KRAPOVICKAS, A. 1996. Agricultura indígena en las llanuras de la Cuenca del Plata. Anales Academia Nacional de Agronomía y Veterinaria. 50 (17): 31-45.

. 1997. Los primitivos recolectores de germoplasma en el Nuevo Mundo. Ciencia e Investigación 50(12): 45-47.

LEÓN, J. 1987. Botánica de los cultivos tropicales. 2a ed., IICA, San José de Costa Rica.

LEROI-GOURHAN, A. 1988. Dictionnaire de la Préhistoire. Presses Universitaires de France, París.

LÓPEZ GIRÓN, J. 1993. Agricultura, en Diccionario temático de antropología, ed. A. Aguirre Bazán, págs: 7-10. Editorial Boixareu Universitaria. Barcelona.

LYNCH, T.F. 1971. Preceramic Trashumance in the Callejón de Huaylas, Perú. American Antiquity 36(2): 139-148.

— 1975. Algunos problemas básicos del estado de Caza-recolección Andina: Trashumancia. Estudios Atacameños 3: 7-10.

—. 1975. La cosecha inoportuna, trashumancia y el proceso de domesticación. Estudios Atacameños 3: $75-80$.

MCLENNAN, J.F. 1865. Primitive Marriage. Tomado de Morgan, 1970: 436.

MORGAN, L.H. 1851. League of the Iroquois (tomado de Ames, 1939: 18).

. 1970. La Sociedad Primitiva. Editorial Ayuso, Madrid ( $1^{\circ}$ ed. 1877). Orquera, 1987.

PARODI, L.R. 1938. El proceso biológico de la domesticación vegetal. Revista Argent. Agron. 5(1):1-24.

PROUS, A. 1992. Arqueologia brasileira. Brasilia, DF. Editora Universidade de Brasilia.

RENFREW, C \& P. BAHN. 1993. Arqueología. Teoría, métodos y práctica. Ediciones Akal, Madrid.

RICHARDSON III, J.B. 1972. The Pre-Columbian Distribution of the Bottle Gourd (Lagenaria siceraria). Economic Botany 26(3): 265-273.

SAUER, C.O. 1950. Cultivated plants of South and Central America. En Handbook of South American Indians, vol. 6, ed. J.H. Steward, Smithsonian Institution, Bureau of American Ethnology, Bulletin 143: 487-543.

SCHMIDT, M. 1951. Anotaciones sobre las plantas de cultivo y los métodos de la agricultura de los indígenas sudamericanos. Revista do Museu Paulista (nov. ser.) 5: 239-255. Sao Paulo, Brasil.

SORIANO, A. \& M. AGUIAR. 1997. Estructura y funcionamiento de los agroecosistemas. Ciencia e Investigación, 50 (3-4): 63-73.

STEBBINS, G. L. 1974. Flowering plants. Evolution above the Species level. Belknap Press, Cambridge, Massachusetts.

STEPHENS, A. 1998. Dictionary of agriculture. Peter Collin Publ. Teddington, Inglaterra

VAVILOV, N.I. 1951. Estudios sobre el origen de las plantas cultivadas. Acme Agency, Buenos Aires. Traducción de Bulletin of Applied Botany and Pantbreeding 16(2), Leningrado, 1926.

WINICK, C. 1961. Dictionary of Anthropology. Littlefield, Adamas \& Co., Paterson, New Jersey. 1969. Diccionario de Antropología. Ediciones Troquel, Buenos Aires. 
WRIGHT, S. 1932. The roles of mutation, imbreeding, crossbreeding and selection in evolution. Proc. VI Int. Congr. Genetics 1: 355-366.

ZOHARY, D. 1970. Centers of diversity and centers of origin. En Genetic Resources in Plants, ed. O.H.
Frankel \& E. Bennett. London.

1992. Domestication of the Neolithic Near Eastern crop assemblage. En P. Anderson (ed.), Prehistoire de 1'Agriculture. Nouvelles expérimentales et ethnographiques, Paría, pp: 81-87.

Original recibido el 30 de octubre de 2011; aceptado el 23 de noviembre de 2011. 